\title{
Dynamics in Attaining Woman Quota of 30\% (Study among Political Parties in Central Java Province Indonesia)
}

\author{
Misbah Zulfa Elizabeth ${ }^{1}$, Ririh Megah Safitri², Naili Ni'matul Illiyyun ${ }^{3}$, \\ Masrohatun $^{4}$, Kaisar Atmaja ${ }^{5}$ \\ Faculty of Social and Political Science State Islamic University Walisongo 1,2,3,4,5 \\ \{zulfa_elizabeth@walisongo.ac.id $\left.{ }^{1}\right\}$
}

\begin{abstract}
The Law on General Elections in Indonesia was a revolution in legislation. However, after three general elections, the $30 \%$ quota that was set for women in the political sphere showed that the quota target was still not met, even in some places it decreased. Applying qualitative research method with a gender approach, the research showed that: 1) Party leaders saw that the enactment of quota for women in political parties was a good policy in an effort to increase women's involvement in the political sphere; 2) Some parties have special efforts to involve women in the political party, although some parties do not have special programs; 3 ) The effort of party has the effect on the number of women of the party in legislative board.The difficulty in achieving the quota was partly due to: lack of common understanding in the party structure regarding quotas, as well as difficulties in getting female cadres.
\end{abstract}

Keywords: 30\% Quota; Women; Political Party; Gender

\section{Introduction}

Formula kebijakan partai politik dan penetapan kuota perempuan sebesar $30 \%$ belum mampu meningkatkan keterlibatan perempuan dalam ranah perpolitikan, bahkan dinamika keterlibatan perempuan dalam politik justru mengarah pada peminggiran perempuan melalui struktur laten pengelolaan partai politik dan pemakluman atas perempuan. Peminggiran peran dan fungsi para kader perempuan dalam aktivitas kepartaian menjadi representasi atas implementasi Undang-Undang nomor 31 tahun 2002 tentang partai politik dan UndangUndang nomor 12 tahun 2003 tentang kuota perempuan dalam pemilihan umum belum optimal. Penyelenggaraan pemilihan umum pasca diterbitkannya undang-undang tersebut faktanya belum menunjukkan keterlibatan perempuan secara signifikan. Seringkali, keterlibatan perempuan hanya dimaknai sebagai pemenuhan syarat operasional partai politik dalam merespon kebijakan. Keterlibatan perempuan dalam aktivitas kepartaian seringkali terkendala oleh hambatan struktural yang terlegitimasi dalam hambatan kultural. Budaya patriarki dan nilai-nilai sosial di Indonesia menuntut perempuan untuk tidak berpartisipasi di ranah politik maupun pemerintahan. Sistem dan arah kebijakan pemerintah terhadap isu 
perempuan kian responsif gender. Namun demikian, posisi perempuan tetap rentan terhadap berbagai bentuk manipulasi politik (Nurcahyo 2016).

Sejauh ini studi terkait keterlibatan perempuan dalam ranah politik seringkali tertuju pada dua hal. Pertama yakni, perihal inkompetensi dan kapasitas perempuan dalam mengisi ruangruang politik dan demokrasi (Mire 2001; Nimrah dan Sakaria, Kunci, and Budaya Patriarki 2015; Nurcahyo 2016). Perempuan, sebagaimana ditunjukkan Tucker, hampir selalu dipandang lemah dan tidak kapabel mengisi posisi strategis dalam bidang politik (Pambudi 2009). Kecenderungan yang kedua tertuju pada kajian yang menitikberatkan pada beban ganda yang melekat pada diri perempuan. Dikhotomi peran publik/produktif dan domestik menjadi kondisi yang dilematis bagi perempuan (Hidayati 2015), bahkan seringkali menjadi kendala dalam partisipasi perempuan di berbagai ranah termasuk politik. Problematika terkait partisipasi perempuan telah menjadi persoalan yang krusial selain terjadi secara massif juga mencoreng demokrasi yang susah payah dibangun. Partisipasi perempuan dalam politik merupakan suatu tanda adanya transisi dari praktik politik otoritarian (Mama 2013). Dengan kata lain, keterbukaan ruang politik bagi perempuan dapat menjadi basis bagi perkembangan demokrasi. Namun demikian, banyak kasus memperlihatkan hal sebaliknya (Simga and Goker 2017).

Tujuan tulisan ini melengkapi kekurangan studi sebelumnya dengan menitikberatkan studi pada pengalaman objektif perempuan dalam politik, khususnya terkait dengan berbagai upaya partai politik dalam mengakomodasi keterlibatan perempuan melalui kuota $30 \%$. Sejalan dengan itu, maka terdapat tiga pertanyaan yang dapat dirumuskan: a) Bagaimana respon partai politik pasca ditetapkannya kebijakan terkait keterwakilan perempuan dengan kuota $30 \%$; b) Bagaimana upaya partai politik dalam memenuhi target keterlibatan perempuan dengan kuota $30 \%$; c) Bagaimana indeks keterwakilan perempuan dalam partai politik di Jawa Tengah.

\section{Theoretical Framework}

Upaya yang dilakukan pemerintah guna meningkatkan kuota 30\% keterwakilan perempuan di parlemen dari tahun 2003 melalui disahkannya UU No. 12 tahun 2003 tentang Pemilihan Umum Anggota Dewan Perwakilan Rakyat (DPR), Dewan Perwakilan Daerah (DPD), dan Dewan Perwakilan Rakyat Daerah (DPRD) serta UU No.2 tentang Partai Politik merupakan upaya rekayasa politik melalui kebijakan perundangan. Rabo (2005) menegaskan bahwa fungsi kebijakan adalah sebagai alat rekayasa budaya. Dalam konteks kajian ini budaya patriarchy merupakan hambatan terbesar bagi masuknya perempuan ke dunia publik dalam bidang politik. Budaya patriarchy adalah budaya menegaskan gagasan tentang pemilahan peran dan fungsi laku-laki dan perempuan dalam ranah hidupnya akibat asumsi dasar terhadap masing-masing jenis kelamin

Pemerintah melalui UU tersebut mengakomodir ruang politik bagi perempuan, meskipun tidak menutup adanya kemungkinan posisi perempuan tidak rentan adanya manipulasi (Nurcahyo 2016). Dominasi laki-laki dalam ranah politik tidak lepas dari mengakarnya budaya patriarki yang lebih mengunggulkan laki-laki dibandingkan perempuan dalam kehidupan masyarakat sehar-hari. Realita ketidakadilan ini jelas tidak responsif gender. Gender menurut Riant Nugroho adalah relasi laki-laki dan perempuan yang ditentukan oleh sistem nilai yang dianut oleh komunitas di mana mereka eksis, berarti makna tersebut bergeser dari waktu ke waktu (Fakih, 2008; Nugroho 2008). Sederhananya jika merujuk definisi tersebut maka partai politik memiliki peran central untuk mengubah stigma negative perempuan berdasar atas apa yang sudah diatur oleh pemerintah terkait pemenuhan kuota 30 
$\%$ perempuan baik dalam porsi struktur kepengurusan maupun dalam menempatkan perempuan pada posisi strategis daftar calon dalam kontestasi politik memperebutkan kursi parlemen.

\section{Literature Review}

Kajian mengenai kebijakan kuota perempuan sebesar 30\% telah banyak dilakukan oleh peneliti. Factor sosial budaya tidak berdampak signifikan dalam partisipasi perempuan, justru sistem voting dan besarnya dana kampanye menghambat partisipasi perempuan (Hillman 2017). Kebijakan kuota 30\% membantu meningkatkan representasi perempuan di berbagai negara berkembang, namun konteks suatu negara menjadi factor yang lebih penting (Rosen 2017). Perempuan terhambat memenuhi kuota karena budaya patriarki yang kuat (Boro and Kale 2020; Parwati and Istiningdiah 2020; Yuwono 2018). Selain itu, nilai agama dan budaya juga menjadi tantangan representasi perempuan dalam berpolitik (Fithriana and Annissa 2016). Laki-laki diprioritaskan daripada perempuan dalam penentuan caleg dan nomor urut partai politik di Kecamatan Boawae NTT (Boro and Kale 2020).

Kebijakan kuota 30 persen dianggap kurang signifikan dalam meningkatkan keterwakilan perempuan karena akses perempuan untuk masuk di parlemen masih lemah (Prastiwi 2018; Umagapi 2020). Keterwakilan perempuan dalam pemilu legislative 2014 dan 2019 cukup terimplementasi, meski hanya terpenuhi ketika pendaftaran caleg yang diajukan partai. Namun demikian, tidak ada jaminan kemenangan perempuan dalam menduduki kursi parlemen meski diterapkan zipper system (Ningrum, Kana, and Haryani 2020; Umagapi 2020). Partai politik merupakan agen pertama yang bertanggung jawab dalam meningkatkan kualitas dan kuantitas politisi perempuan (Purwanti 2015). Selain itu, partai politik memiliki kewajiban dalam menyuarakan kesetaraan gender dan mereview kebijakan kuota dan zipper system agar proporsional (Prastiwi and Haliim 2018). Lebih jauh, penafsiran ulang terhadap teks-teks keagamaan dan pendidikan responsive gender juga diperlukan sebagai upaya jangka panjang mewujudkan partisipasi perempuan dalam berpolitik (Yeni 2017).

\section{Results and Discussion}

Pandangan pimpinan partai. Pada umumnya partai politik memandang positif terhadap penetapan quota $30 \%$ perempuan untuk duduk di di ranah politik, dari level partai hingga level menjadi anggota legislatif. Dari enam informan yang merupakan pimpinan partai politik, baik partai politik yang berbasis agama, berbasis massa agama, maupun partai politik dengan basis ideologi nasionalis, semua menyatakan dukungan terhadap penetapan quota $30 \%$. Salah seorang pimpinan partai menyatakan bahwa: "untuk era sekarang, ketika perempuan telah menapaki pendidikan yang setara dengan laki-laki maka sangat wajar jika perempuan juga sudah mulai menduduki jabatan publik dalam bidang politik, seperti sebagai anggota legislative". Pimpinan partai lain menyatakan dukungannya dengan alasan bahwa ketetapan itu merupakan ketetapan undang-undang sehingga harus diterima. Ekspresi dukungan dari pimpinan partai itu dinyatakan dalam berbagai event kepartaian maupun event publik yang diadakan oleh partai politik, organisasi perempuan maupun organisasi massa lain.

Melihat beberapa pernyataan di atas dapat dipahami bagaimana gagasan dasar para pimpinan partai berkait dengan keterlibatan perempuan di ranah politik. Beberapa point dapat ditegaskan di sini. Pertama bahwa para pimpinan itu mau tidak mau menerima gagasan 
tentang quota karena gagasan ini merupakan gagasan global (Agassi, 2008). Oleh karena itu tidak mungkin bagi mereka menyatakan penolakannya atas perundangan nasional yang memang secara global telah menjadi concern (Dahlerup ed., 2013) Kedua, sikap penerimaan ini juga merupakan politik partai dalam kerangka "image building" bahwa partai peduli terhadap perempuan. Image diri partai ini penting dalam rangka untuk merebut suara.

Upaya Partai dalam Mencapai Target Kuota. Tata aturan organsasional partai termuat dalam Anggaran Dasar dan Anggaran Rumah Tangga Partai. Anggaran Dasar dan Anggaran Rumah Tangga Partai dibahas dan diputuskan pada forum Musyawarah Nasional Partai yang merupakan forum tertinggi partai karena dalam forum itu diputuskan arah kebijakan dan ketentuan baru partai, selain juga dipilih ketua partai yang baru. Forum tersebut diadakan setiap suatu kurun waktu tertentu, namun pada umumnya dilaksanakan setiap lima tahun sekali.

Hasil dari keputusan partai berkait dengan target pemenuhan quota $30 \%$ perempuan adalah bahwa ada dua fenomena mengenai upaya partai dalam memenuhi kuota perempuan $30 \%$ di legislative. Yang pertama adalah membentuk organisasi sayap partai yang merupakan organisasi perempuan partai, sebagai contoh Perempuan Bangsa PKB, Perempuan PPP, Perempuan PAN (PUAN). Organisasi sayap seperti ini merupakan organisasi partai yang dikelola oleh perempuan dan membahas program yang berkait dengan perempuan. Fenomena kedua adalah menginklusikan program perempuan dalam partai. Contohnya adalah yang dibentuk oleh Partai Demokrasi Indonesia Perjuangan (PDIP) 25 Agustus 2009, dengan program "PDI Rumah Perempuan".

Asumsi dasar dari kedua strategi itu berbeda, namun orientasinya sama-sama untuk meningkatkan partisipasi perempuan dalam politik. Organisasi sayap dibentuk dengan asumsi bahwa persoalan perempuan akan lebih baik jika ditangani secara khusus oleh perempuan. Sementara itu strategi inklusi berasumsi bahwa partai harus terbuka terhadap keragaman, termasuk jenis kelamin, sehingga perempuan harus dilibatkan dalam keorganisasian partai secara langsung.

Dampak dari strategi itu tentu beragam sesuai dengan kondisi organisasi dan juga konstituennya. Partai politik dengan organisasi sayap memiliki keragaman dampak dari kemajuan dalam mendapatkan anggota perempuan. Sebagai contoh, pertama, partai dengan basis massa agama memiliki kaitan erat dengan organisasi basisnya. Kedua, partai politik yang memiliki sejarah electoral panjang juga memiliki basis massa yang luas, dan Ketiga, partai dengan basis ideologi yang mendapatkan basis pemilihnya dari kesamaan ideologi. Sementara itu strategi inklusi yang dilakukan oleh PDI-Perjuangan membuka kemungkinan perempuan untuk semakin terlibat dalam aktifitas di partai politik. Konsekuensi dari keterbukaan yang menjadi statemen partai, dalam kepengurusan 2009 PDI Perjuangan telah merombak kepengurusan partai dengan prinsip yang mengakomodir keterlibatan perempuan sebanyak $30 \%$.

Hasil dari Kebijakan Partai terhadap Pencapaian Kuota. Adanya kebijakan partai yang secara serius memandang persoalan rendahnya keterlibatan perempuan dalam dunia politik telah memunculkan beberapa fenomena tentang hasil dari upaya yang dilakukan oleh partai. Dari sepuluh partai yang terwakili di DPRD Jawa Tengah, dengan pengamatan pada tiga kali masa kerja DPRD, yaitu 2009-2014, 2014-2019 dan 2019-2024 tampak bahwa Partai Demokrasi Indonesia Perjuangan, Partai Kebangkitan Bangsa, dan Partai Persatuan Pembangunan, memiliki tingkat keterwakilan perempuan yang terus meningkat. Tabel 1 menunjukkan peningkatan itu. 
Tabel 1. Partai di DPRD Jawa Tengah Dengan Jumlah Perempuan yang Meningkat

\begin{tabular}{cccc}
\hline Partai & 2009-2014 & 2014-2019 & 2019-2024 \\
\hline PDI-P & 6 & 10 & 10 \\
PKB & 1 & 3 & 4 \\
PPP & - & 2 & 4 \\
\hline
\end{tabular}

Sumber: Analisis Data Primer

Partai Demokrasi Indonesia Perjuangan memiliki wakil perempuan di legislative yang cukup banyak karena basis massa yang luas serta affirmasi partai dengan program "PDIP Rumah Perempuan" yang berjalan efektif. Sementara partai Kebangkitan bangsa dan Partai Persatuan Pembangunan memiliki wakil perempuan yang tinggi karena kaderisasi perempuan di organisasi massa basis kuat sehingga mampu menyediakan kader yang masuk dunia politik. Fenomena ini menunjukkan adanya perubahan angka keterlibatan perempuan dalam kancah politik sebagaimana dinyatakan oleh Ardiansa (2017) sebagai upaya menghadirkan representasi perempuan dalam dunia politik yang secara budaya merupakan proses kesadaran partai mengenai arti penting keterlibatan perempuan dalam politik (Agassi, 2008).

\section{Conclusion}

Pernyataan pimpinan partai tidak lepas dari image building partai terhadap akomodasi perempuan dalam dunia politik. Oleh karena itu apa yang disampaikan oleh pimpinan partai selalu diorientasikan untuk assesibilitas partai bagi para konstituen. Oleh karena itu ekspresi dari para pimpinan partai adalah mendukung kebijakan negara untuk kuota $30 \%$ bagi perempuan.

Meskipun regulasi negara dan sikap dan pernyataan para pimpinan partai mendukung kuota perempuan $30 \%$, namun dalam tataran manajemen organisasi partai, partai-partai ini memiliki keragaman dalam mengimplementasikan. Pandangan patriarchy masih demikian kuat sehingga support terhadap perempuan di dalam partai belum tampak sepenuhnya.

Peningkatan jumlah perempuan yang masuk ke dalam dunia politik, dan menjadi anggota legislative merupakan ekspresi dari upaya partai untuk melakukan affirmasi terhadap pencapaian kuota $30 \%$ untuk perempuan, meskipun faktor lain juga menentukan, seperti organisasi basis serta ketersediaan perempuan yang siap masuk dunia politik.

\section{References}

[1] Agassi, J. B. 2008. "Gender Studies." in International Encyclopedia of the Social Sciences, edited by W. A. Darity. Gale Cengage Learning.

[2] Ardiansa, D. 2017. "Menghadirkan Kepentingan Perempuan Dalam Representasi Politik Di Indonesia." Jurnal Politik 2(1):71-99.

[3] Boro, Veronika Ina Assan, and Alexander Efraim Tad Kale. 2020. "Keterwakilan Perempuan Di Ranah Lokal: Studi Kasus Di Kecamatan Boawae, Nusa Tenggara Timur Dalam Pemilu Legislatif 2014." Politika: Jurnal Ilmu Politik 11(1):115-30.

[4] Dahlerup, D. ed. 2013. Women, Quotas and Politics. London: Routledge.

[5] Fakih, M. 2008. Analisis Gender Dan Transformasi Sosial. Yogyakarta: Insist Press.

[6] Fithriana, Arin, and Jeanie Annissa. 2016. "Perbandingan Kualitas Demokrasi Dalam Perspektif Kesetaraan Gender Antara Indonesia Dan Thailand." Jurnal Sawala $4(2): 12-24$. 
[7] Hidayati, Nurul. 2015. "Beban Ganda Perempuan Bekerja (Antara Domestik Dan Publik)." Muwazah.

[8] Hillman, Ben. 2017. "The Limits of Gender Quotas: Women's Parliamentary Representation in Indonesia." Journal of Contemporary Asia 1-17.

[9] Mama, Amina. 2013. "Women in Politics." in Routledge Handbook of African Politics.

[10] Mire, Amina. 2001. "In/Through the Bodies of Women : Rethinking Gender in African Politics." Polis.

[11] Nimrah dan Sakaria, Siti, Kata Kunci, and dan Budaya Patriarki. 2015. "Perempuan Dan Budaya Patriarki Dalam Politik (Studi Kasus Kegagalan Caleg Perempuan Dalam Pemilu Legislative 2014 ).” The POLITICS: Jurnal Magister Ilmu Politik Universitas Hasanuddin.

[12] Ningrum, Tanti Setia, Philips A. Kana, and Riastri Haryani. 2020. "Analisis Yuridis Keterwakilan Perempuan Dalam Pengisian Keanggotaan Parlemen Dalam Perspektif Hukum Tata Negara Indonesia." Jurnal Krisna Law 2(1):53-68.

[13] Nugroho, Riant. 2008. Gender Dan Administrasi Publik. Yogyakarta: Pustaka Belajar.

[14] Nurcahyo, Abraham. 2016. "Relevansi Budaya Patriaki Dengan Partisipasi Politik Dan Keterwakilan Perempuan Di Parlemen." Agastya 06.

[15] Pambudi, Mohammad Yusuf. 2009. "Perempuan Dan Politik Studi Tentang Aksesibilitas Perempuan Menjadi Anggota Legislatif Di Kabupaten Sampang." Ilmu Politik FISIP, Universitas Airlangga, Surabaya.

[16] Parwati, Theresia, and Kuspuji Istiningdiah. 2020. "Partisipasi Dan Komunikasi Politik Prempuan Di Legislatif Menurut Kacamata Politisi Perempuan Di Indonesia." Interaksi: Jurnal Ilmu Komunikasi 9(2):119-29.

[17] Prastiwi, Juwita Hayyuning. 2018. "Menakar Kontribusi UU Pemilu Tahun 2017 Terhadap Peningkatan Keterwakilan Perempuan.” Jurnal Wacana Politik 3(1):1-13.

[18] Prastiwi, Juwita Hayyuning, and Wimmy Haliim. 2018. "Politisi Perempuan Dan Korupsi: Mencari Solusi Atas Dilema Politik Kesetaraan Gender Di Era Reformasi." Kafa'ah Journal 8(1):71-83.

[19] Purwanti, Ani. 2015. "Quota Law's for Women in Politics: Implementation in Indonesia." South East Asia Journal of Contemporary Business, Economics, and Law 6(4):28-36.

[20] Rabo, A. 2005. "Free to Make the Right Choice? Gender Equality Policy in PostWelfare Sweden." P. 107 in Anthropology of Policy: Critical Perspectives on Governance and Power, edited by Cris Shore and Susan Wright.

[21] Rosen, Jennifer. 2017. "Gender Quotas for Women in National Politics: A Comparative Analysis across Development Thresholds." Social Science Research 120.

[22] Simga, Hulya, and Gulru Z. Goker. 2017. "Whither Feminist Alliance? Secular Feminists and Islamist Women in Turkey." Asian Journal of Women's Studies.

[23] Umagapi, Juniar Laraswanda. 2020. "Representasi Perempuan Di Parlemen Hasil Pemilu 2019: Tantangan Dan Peluang." Kajian 25(1):19-34.

[24] Yeni, Saadah Erma. 2017. "Perempuan Berdaya Tawar: Tantangan Dan Peluang Partisipasi Politik Perempuan." Agenda 1(1):159-71.

[25] Yuwono, Nurbaity Prastyananda. 2018. "Perempuan Dalam Kungkungan Budaya Politik Patriarkhis." Muwazah Jurnal Kajian Gender 10(2):96-115. 